\title{
Essential role of endogenous prolactin and CDK7 in estrogen- induced upregulation of the prolactin receptor in breast cancer cells
}

\author{
Raghuveer Kavarthapu ${ }^{1}$, Maria L. Dufau ${ }^{1}$ \\ ${ }^{1}$ Section on Molecular Endocrinology, Eunice Kennedy Schriver National Institute of Child Health and Human Development, \\ National Institutes of Health, Bethesda, MD 20892-4510, USA \\ Correspondence to: Maria L. Dufau, email: dufaum@mail.nih.gov \\ Keywords: estrogen receptor, prolactin, prolactin receptor, estradiol, STAT5 \\ Received: November 17, 2016 \\ Accepted: February 18, 2017 \\ Published: March 09, 2017 \\ Copyright: Kavarthapu et al. This is an open-access article distributed under the terms of the Creative Commons Attribution \\ License (CC-BY), which permits unrestricted use, distribution, and reproduction in any medium, provided the original author and \\ source are credited
}

\section{ABSTRACT}

Our early studies have shown that Estradiol $\left(E_{2}\right) /$ Estrogen Receptor $\alpha(E R)$ in a non-DNA dependent manner through complex formation with C/EBPB/SP1 induced transcriptional activation of the generic hPIII promoter and expression of the Prolactin Receptor (PRLR) receptor in MCF-7 cells. Subsequent studies demonstrated effects of unliganded ER $\alpha$ with requisite participation of endogenous PRL on the activation of PRLR transcription. Also, EGF/ERBB1 in the absence of PRL and $E_{2}$ effectively induced upregulation of the PRLR. In this study we have delineated the transcriptional mechanism of upregulation of PRLR receptor induced by $E_{2}$ incorporating knowledge of the various transcriptional upregulation modalities from our previous studies. Here, we demonstrate an essential requirement of STAT5a induced by PRL via PRLR receptor which associates at the promoter and its interaction with phoshoERa S118. Knock-down of PRL by siRNA significantly reduced $E_{2}$-induced PRLR promoter activity, mRNA and protein expression, recruitment of ERa to the complex at promoter, C/EBP $\beta$ association to its DNA site and productive complex formation at hPIII promoter. The specific CDK7 inhibitor (THZ1) that attenuates $\mathrm{E}_{2}$-induced ERa phosphorylation at $\mathbf{S 1 1 8}$ abrogated $E_{2}$-induced PRLR promoter activation. Further studies demonstrated that $E_{2}$ induced cell migration was inhibited by PRL siRNA and THZ1 indicating its dependence on PRL/PRLR and CDK7, respectively. Our studies have demonstrated the essential role of endogenous PRL and CDK7 in the upregulation of PRLR by $E_{2}$ and provide insights for therapeutic approaches that will mitigate the transcription/expression of PRLR and its participation in breast cancer progression fueled by $E_{2}$ and $P R L$ via their cognate receptors.

\section{INTRODUCTION}

Prolactin Receptor (PRLR) belongs to the class I cytokine receptor superfamily. The long form of PRLR has an extracellular domain, a single transmembrane domain and intracellular cytoplasmic domain which is required for signal transduction. Prolactin (PRL) hormone binds to PRLR with high affinity and mediates its actions predominantly through JAK-2/STAT5 signaling pathway and other pathways that involve MAPK and the participation of JAK $2 / \mathrm{c}-\mathrm{SRC}$ family kinases/ focal adhesion kinase via phosphatidylinositol 3-kinase
[1-3]. PRLR is well known to play an important role in the physiology of the human breast and in the etiology, progression breast cancer [4-6]. Also, substantial clinical and etiological evidence indicates that estrogen exposure promotes the development, progression and invasion of breast cancer. Its effects are mediated via estrogen receptors through a host of estrogen responsive genes [79], and through signaling pathways generate through nongenomic pathways [10]. ER-independent effects resulting from direct genotoxic insult of its metabolites have been also recognized [11]. An important connection has been established between ER $\alpha$ and PRLR where both liganded 
and un-liganded ER $\alpha$ were found to participate in PRLR regulation $[12,13]$.

Our previous studies demonstrated upregulation of transcription/expression of the PRLR gene by estradiol through its preferential utilized promoter PIII promoter (hPIII/hE1 $1_{3}$ ), which is one of six promoters of the hPRLR gene with their corresponding alternative non-coding exons 1. Among these, in addition of the generic promoter 1/exon1 ( $\left.\mathrm{hPIII} / \mathrm{hE} 1_{3}\right)$ which is also present in rat and mouse, the other five are human specific (promoters 1-5/ exon1-5, $\left.\mathrm{hE}_{\mathrm{N} 1-5}\right)$ [14-16]. Estradiol $\left(\mathrm{E}_{2}\right)$ through activation of the hPIII promoter lacking an estrogen responsive element induce increases of PRLR non-coding exon$1 \mathrm{hE} 1_{3}$ mRNA transcripts, PRLR mRNA and protein. The hPIII promoter contains functional $\mathrm{Sp} 1$ and $\mathrm{C} / \mathrm{EBP}$ sites that bind $\mathrm{Sp} 1 / \mathrm{Sp} 3$ and $\mathrm{C} / \mathrm{EBP} \beta$, respectively. NonDNA bound $\mathrm{ER} \alpha$ activated by $\mathrm{E}_{2}$ associates in a complex with $\mathrm{Sp} 1$ and $\mathrm{C} / \mathrm{EBP} \beta$ bound to their cognate elements. These in turn recruit coactivators and through epigenetic changes favor the recruitment of TFIIB, and Pol II for transcriptional induced expression of PRLR gene by $\mathrm{E}_{2}$ in MCF-7 breast cancer cells $[12,17]$.
In related studies we demonstrated that ER $\alpha$ preexist as homodimers even in absence of $\mathrm{E}_{2}$, and that a conformation change in $\mathrm{ER} \alpha$ induced by $\mathrm{E}_{2}$ has an important role in its increased interaction with $\mathrm{C} / \mathrm{EBP} \beta$ and $\mathrm{Sp} 1$ [18].

Our recent studies revealed upregulation of the PRLR induced by endogenous and exogenos prolactin (PRL) through its receptor in the absence of estradiol in MCF-7 and T47D-cells where unliganded-ER $\alpha$, JAK2/ STAT5, mitogen-activated protein kinase (MAPK) and PI3K pathways were found to have essential roles. Phospho- ER $\alpha$ associates with the C/EBP $\beta$-SP1 as complex at the PRLR hPIII promoter. JAK2- activated STAT5a and $\mathrm{b}$ (phospho-forms) associate as tetramer of homodimers or heterodimers with a functional GAS element in the noncoding exon $1\left(\mathrm{hE1}_{3}\right)$ corresponding to the hPIII promoter [13]. This exon was found in our previous studies to be required for the transcriptional activity of the hPIII promoter (Figure 1A, left) $[15,16]$. Other recent studies have indicated a role for paracrine EGF via EGFR/ERBB1 independent of estrogen and prolactin in the transcriptional activation of PRLR gene expression. Unliganded ER $\alpha$ and STAT5b, which are both phosphorylated by EGF-induced activation of EGFR/ERRB1 through separate independent
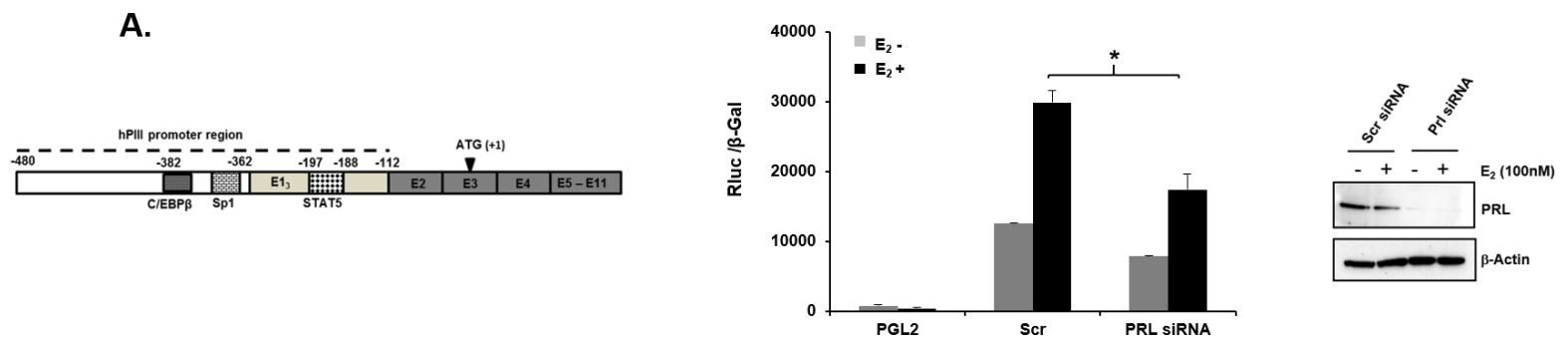

B.

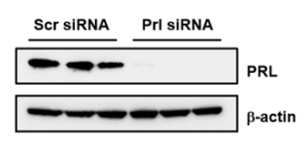

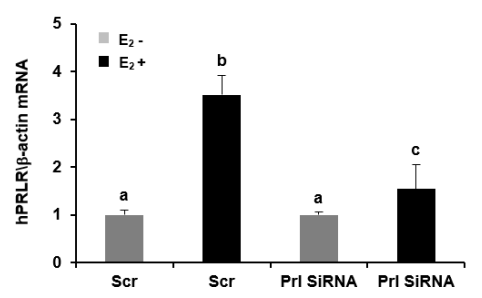

C.

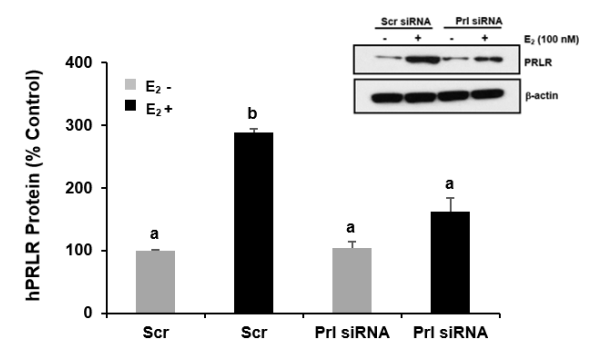

Figure 1: E2 induced upregulation of PRLR gene transcription/expression inhibited by knock-down of endogenous PRL. (A) Left- Schematic representation of PRLR gene with the generic promoter hPIII (indicated in dotted line -480/-112) which includes the non-coding exon-1 $\left(\mathrm{hE}_{3}\right)$ required for promoter activity $[15,16]$ and also the DNA sites of relevant transcription factors within hPIII are indicated. In addition the common non-coding exon 2 and coding exons 3-11 are shown. Right- Effect of $\mathrm{E}_{2}$ (100 nM) on PRLR promoter activity in cells transfected with PGL2 construct (control) or wild type hPIII/hE1 and with/without Scrambled (Scr) or PRL siRNAs. Results presented are relative luciferase activities (Rluc) normalized to the activities of co-transfected $\beta$-galactosidase. Asterisks $\left(^{*}\right)$ indicate statistically significant reduction in PRL siRNA treated group induced by $\mathrm{E}_{2}$ compared to Scr siRNA treated group induced by $\mathrm{E}_{2}$ (Student $t$-test; $P<0.01$ ). Relative mRNA (B) and protein expression (C) levels of PRLR normalized by endogenous $\beta$-actin upon $\mathrm{E}_{2}$ induction in MCF-7 cells transfected with either Scr or PRL siRNAs. Left- Western blot of PRL protein expression in Scr siRNA and PRL siRNA transfected samples. Different superscript letters indicate significant differences (Tukey's multiple comparison test, $P<0.05$ ). (C) RightWestern blot PRLR protein expression in Scr siRNA and PRL siRNA transfected samples (right). Results in this figure and below are reported as the mean $\pm \mathrm{SE}$ of three independent experiments. 
mechanisms, are both required in the PRLR activation of gene expression by EGF [19]. Of major relevance were our findings whereby interaction of ER $\alpha$ with STAT5 at the promoter was found to be required for association of phospho-ER $\alpha$ to the complex with consequent induction of the PRLR gene by PRL or EGF. These findings were indicative of STAT5 as stabilizing factor on unliganded $\mathrm{ER} \alpha$ association to the complex at the PIII promoter.

Since PRLR and EGFR are expressed in breast tumors and STAT5 was found essential for unliganded $\mathrm{ER} \alpha$ dimer association with the complex at the PRLR promoter [13, 19], we envisioned commonalities in the mechanism that participate in the $\mathrm{E}_{2} / \mathrm{ER} \alpha$ induction of PRLR gene transcription/expression to that observed for PRL and EGF in MCF-7 cells. Thus, it was of much interest to apply our current knowledge to further studies on the intrinsic mechanism of upregulation of PRLR by $\mathrm{E}_{2} / \mathrm{ER} \alpha$. Phosphorylation of $\mathrm{ER} \alpha$ is effectively induced by $\mathrm{E}_{2}$ at $\mathrm{S} 118$ in the AF1 domain via cyclin dependent kinase CDK7/cyclin H complex [20] and JAK2 derived signal transduction pathways, MAPK and PI3K, induced by endogenous PRL via PRLR could also contribute to ER $\alpha$ phosphorylation. Moreover, since other aspects of the PRL/ PRLR/JAK2/STAT5 are of relevance in transcriptional activation of PRLR we proceeded to investigate their role in the $E_{2} / E R \alpha$ upregulation of the PRLR. In this study we demonstrated the requirement of the participation of PRL/ PRLR in transcriptional upregulation/expression of the PRLR induced by $\mathrm{E}_{2} / \mathrm{ER} \alpha$ in breast cancer cells.

\section{RESULTS}

\section{PRL is required for $E_{2}$ induced PRLR transcription/ expression}

In previous studies we determined that endogenous PRL which is present in breast cancer cells contributes to basal levels of PRLR expression in MCF-7 and T47D cells and these were magnified by addition of exogenous PRL. Also, in early studies we demonstrated that $\mathrm{E}_{2} /$ $\mathrm{ER} \alpha$ induces upregulation of PRLR transcription. We initiated studies to determine whether endogenous PRL action in breast cancer cells is required for $\mathrm{E}_{2}$ induced increase in PRLR gene expression. Cells cultured in the absence of $E_{2}$ transfected with PRL siRNA showed marked depletion of endogenous PRL levels compared to control cells transfected with scrambled siRNA. Control cells (Scrambled siRNA) upon $\mathrm{E}_{2}$ stimulation showed significant increases in PRLR promoter (hPIII generic) activity (Figure 1A), PRLR mRNA (Figure 1B) and protein levels (Figure 1C) by $\mathrm{E}_{2}$ over basal. In contrast, minimal or non-significant increases of these parameter induced by $\mathrm{E}_{2}$ were observed in cells where endogenous PRL was depleted by PRL siRNA, (Figure 1). These findings indicate that endogenous PRL is required for the increases in PRLR induced by $\mathrm{E}_{2}$ in breast cancer cells.

\section{Role of STAT5 in the stimulation of PRLR by $\mathrm{E}_{2} / \mathbf{E R \alpha}$}

Subsequent studies were directed to determine the mechanism of the PRL participation for the increase in PRLR induced by $\mathrm{E}_{2}$. In cells transfected with hPIII WT PRLR promoter $\mathrm{E}_{2}$ significantly stimulated the promoter activity while in cells transfected with hPIII with mutated STAT5 element, residing in non-coding exon-1 of the PRLR promoter, the activation by $\mathrm{E}_{2}$ was minimally present (Figure 2A). This indicated that PRL/ PRLR through activation JAK2 and Stat5 is required for the $\mathrm{E}_{2} / \mathrm{ER} \alpha$ stimulus of PRLR. Activated STAT5 induced by PRL independent of $\mathrm{E}_{2}$ associates with STAT5 DNA element to stimulate PRLR transcription [13]. In the case of the PRLR increase through $\mathrm{E}_{2}$ stimulation the findings indicate the requisite participation of PRL in STAT5 activation. Since in previous studies PRLinduced STAT5 activation in absence of $\mathrm{E}_{2}$ and $\mathrm{ER} \alpha$ was found to interact with STAT5 in Re-ChIP assay [13], we initially investigated whether STAT5a or STAT5b associated with ER $\alpha$. Immunoprecipitates of cells cultured in presence or absence of $\mathrm{E}_{2}$ with STAT5a and STAT5b antibodies revealed that only STAT5a interacts with ER $\alpha$. Furthermore an association of phospho ER $\alpha$ at S118 with STAT5a was demonstrated (Figure 2B). In cultures where STAT5a or STAT5b was significantly depleted by their corresponding siRNAs (Figure $2 \mathrm{C}$, right panel), $E_{2}$ stimulation of PRLR mRNA expression was completely abolished in STAT5a depleted cultures while no effects were observed in the case of cells with depleted STAT5b (Figure 2C).

We previously demonstrated that $\mathrm{ER} \alpha$ associates in a DNA independent manner to $\mathrm{C} / \mathrm{EBP} \beta / \mathrm{Sp} 1$ which in turn associate at their DNA sites at the hPIII promoter [18] and this was markedly enhanced by $\mathrm{E}_{2}$ treatment of cells with complex formation of $\mathrm{E}_{2} / \mathrm{ER} \alpha .-\mathrm{C} / \mathrm{EBP} \beta / \mathrm{Sp} 1$ $[12,18]$ Studies on the association of these transcription factors to the hPIII promoter revealed that in cells with knock-down of endogenous PRL by specific siRNA (Left, Figure 3 Above), recruitment of ER $\alpha$-induced by $\mathrm{E}_{2}$ was significantly decreased compared to controls with scrambled siRNA (Figure 3A) Also, the increased recruitment of $\mathrm{C} / \mathrm{EBP} \beta$ to the promoter induced by $\mathrm{E}_{2}$ in control cells was completely abolished by PRL knockdown (Figure 3B). Sp1 is constitutive associated to the hPIII promoter and $\mathrm{E}_{2}$ as in previous studies did not induce recruitment. However, it is apparent that in cells with PRL depleted Sp1 recruitment was markedly reduced and no significant differences were observed in presence or absence of $\mathrm{E}_{2}$ (Figure 3C). Recruitment of STAT5a, presumably induced by endogenous PRL/PRLR, in control cells was not influenced by $\mathrm{E}_{2}$ treatment. Consequently in cells with PRL knock-down STAT5a was significantly reduced and no differences were observed in presence or absence of estradiol (Figure 3D). The protein expression 
A.

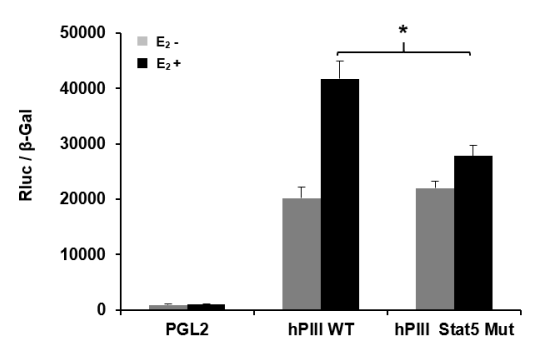

C.

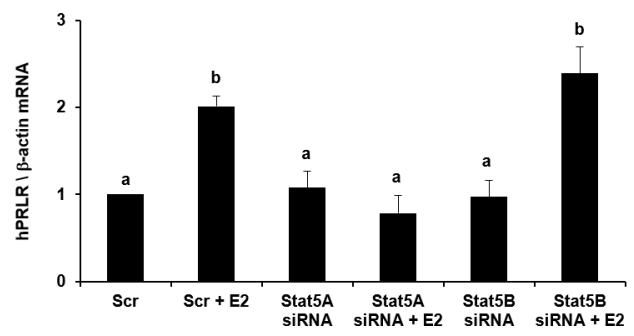

B.

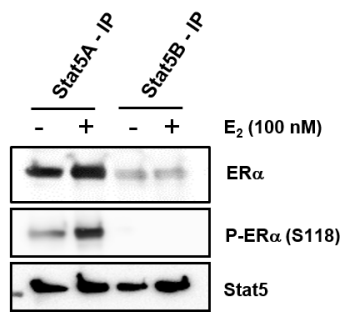

Figure 2: Role of STAT5 in E2-induced promoter activity and mRNA expression of PRLR. (A) Effect of $E_{2}$ on PRLR promoter activity of cells transfected with pGL2 vector (basal) or hPIII construct (WT) or hPIII construct with mutation in STAT5 binding site. Asterisk $\left.{ }^{*}\right)$ indicate the statistically significant reduction in $\mathrm{E}_{2}$-induced cells transfected with hPIII construct with mutation in STAT5 binding site when compared with $\mathrm{E}_{2}$ induced cells transfected hPIII construct (WT) (Student $t$-test; $P<0.01$ ). (B) Immuno-precipitation analysis showing interaction between ER $\alpha / \mathrm{pER} \alpha$ and STAT5a in MCF-7 cells treated in presence or absence of $\mathrm{E}_{2}$. (C) Left- Expression of PRLR mRNA in cells transfected with coding region of STAT5a siRNA or STAT5b siRNA or Scr siRNA. Right- Western blot showing knock-down of STAT5a and STAT5b by siRNA. Different superscript letters indicate significant differences (Tukey's multiple comparison test, $P<0.05$ ).

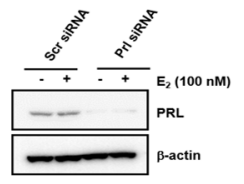

A.

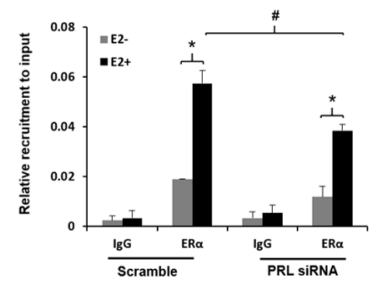

C.

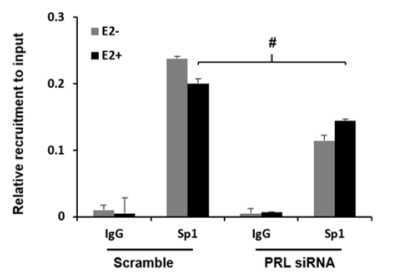

B.

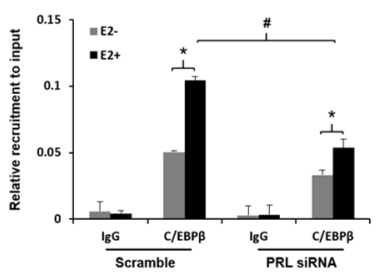

D.

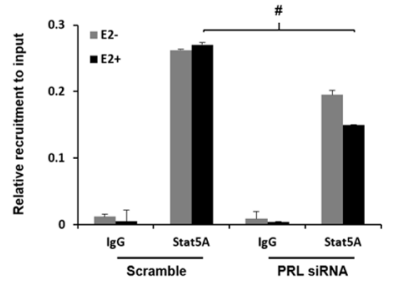

E.

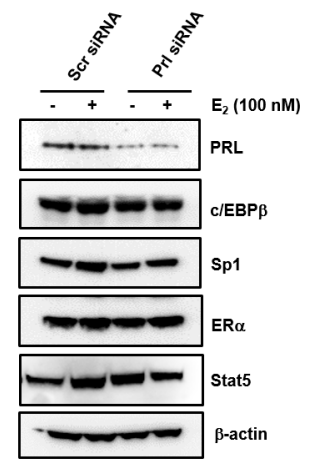

Figure 3: Effect of endogenous PRL knockdown on Recruitment of ER $\alpha$, Sp1, C/EBP $\beta$ and STAT5a on to the PRLR promoter. Above- Western blot of MCF-7 Cells transfected with Scr siRNA or PRL siRNA for $48 \mathrm{~h}$ subsequently incubated with $\mathrm{E}_{2}$ or ethanol (control) after serum starvation for 2 days showing depletion of endogenous PRL by siRNA vs Scr siRNA for A-D shown below. ChIP assay was performed using these cells to observe the recruitment of $\operatorname{ER} \alpha(\mathbf{A}), \mathrm{C} / \operatorname{EBP} \beta(\mathbf{B}), \operatorname{Sp} 1$ (C) and STAT5a (D) onto the PRLR promoter. Asterisks ${ }^{*}$ ) indicate statistically significant changes between $\mathrm{E}_{2}$ untreated and treated groups (Student-t test; $P<0.001$ ). Hash (\#) indicate statistically significant changes between Scr and PRL siRNA transfected groups E (Student-t test; $P<0.05$ ). Western blot showing depletion of endogenous PRL by siRNA versus Scr siRNA, and unchanged levels of ER $\alpha, \mathrm{C} / \mathrm{EBP} \beta, \mathrm{Sp} 1$ and STAT5a expression in PRL depleted versus control cells. 
of these transcription factors were not influenced by the depletion of endogenous PRL (Figure 3E).

\section{Role of CDK7 in the $\mathrm{E}_{2} / \mathrm{ER} \alpha$ induced PRLR transcription}

Subsequent studies in MCF7 cells demonstrated phosphorylation of ER $\alpha$ at Ser 118 in a ligand-dependent manner by CDK7 [20] inhibited by the specific covalent CDK7 inhibitor THZ1 [21], while the AG490 (JAK2 inhibitor) or MEK inhibitor had no effect (Figure 4A and $4 \mathrm{~B}$ ). Further studies demonstrated that the CDK7 inhibitor completely abrogated the stimulation of hPIII PRLR promoter activity by E2 (Figure 4C). Moreover, THZ1 treatment of MCF7 cells caused complete inhibition of $\mathrm{E}_{2}$-induced recruitment of ER $\alpha$ to the hPIII promoter versus basal control (Figure 4D). These findings indicate that inhibition of $\mathrm{E}_{2}$-induced $\mathrm{ER} \alpha$ (S118) phosphorylation by the CDK7 inhibitor contributed to the near complete inhibition of $\mathrm{E}_{2}$-induced PRLR promoter activation.

\section{Role of endogenous PRL and CDK7 in $\mathbf{E}_{2}$ induced cell migration}

To assess whether endogenous PRL and CDK7 have a role in $\mathrm{E}_{2}$-induced cell migration we performed wound healing/scratch assays in MCF-7 cells exposed to THZ1 inhibitor (Figure 5A) or PRL siRNA (Figure 6A), before $\mathrm{E}_{2}$ treatment in serum starved conditions. In untransfected (control) or scrambled (Scr) siRNA transfected cells, percentage wound gap was significantly narrower under $\mathrm{E}_{2}$ treatment than untreated controls. THZ1 treatments (Figure 5A) and knockdown of endogenous PRL by PRL siRNA (Figure 6A) resulted in increased wound gap in the cells with or without $\mathrm{E}_{2}$ induction. Similarly, the inhibitory role of the $\mathrm{CDK} 7$ inhibitor on $\mathrm{E}_{2}$-induced cell migration was demonstrated by Transwell assays (Figure 5B). Also, significant reduction of $\mathrm{E}_{2}$ induced cell migration was observed when endogenous PRL was knock-down by siRNA (Figure 6B). These results indicate that both endogenous PRL and CDK7 are involved in $\mathrm{E}_{2}$-induced cell migration in MCF-7 cells. The findings derived from migration studies are of much relevance since these resemble the essential role of PRL and CDK7 in PRLR upregulation induced by $\mathrm{E}_{2} / \mathrm{ER} \alpha$ (Figures 1-5), and PRLR is require to mediate the actions of PRL.

\section{DISCUSSION}

In this study we have analyzed the intrinsic mechanism of the PRLR upregulation induced by Estradiol via its ERa receptor previously recognized in our laboratory $[12,18]$. We were prompted by our subsequent findings on the modalities of upregulation of the PRLR receptor by un-liganded ER $\alpha$ [13], and its independent regulation by Epidermal Growth through its receptor EGF/
ERBB1 [19]. The finding of a functional GAS site in noncoding exon-1 [13] which is contained in the hPIII of the PRLR participating in both aspects of regulation provided fertile ground to expand our knowledge on the mechanism of $\mathrm{E}_{2} / \mathrm{ER} \alpha$.

In this study we demonstrate the essential role of endogenous PRL in the upregulation PRLR induced by $\mathrm{E}_{2} / \mathrm{ER} \alpha$ with a requisite participation of STAT5a induced by PRL via PRLR. Phosphorylated STAT5a which associates with its functional element at hPIII interacts with non-DNA bound $\mathrm{E}_{2} / \mathrm{ER} \alpha$ which in turn associates in a complex to $\mathrm{Sp} 1$ and $\mathrm{C} / \mathrm{EBP} \beta$ bound to their cognate DNA sites at the PRLR hPIII promoter. $\mathrm{E}_{2}$ favors ER $\alpha$ phosphorylation at S118 by CDK7 kinase, (Figure 4A) and greatly increase the recruitment of $\mathrm{E}_{2} / \mathrm{ER} \alpha$ to the PRLR promoter over basal unliganded $\mathrm{ER} \alpha$ and its association with pSTAT5a (Figure 2B). Phosphorylation of ER $\alpha$ at S118 is necessary for its association to the complex and its interaction with STAT5a. Inhibition by the specific CDK7 inhibitor, THZ1 markedly reduced the $\mathrm{E}_{2}$-induced ER $\alpha$ phosphorylation at S118, while the JAK2 inhibitor AG490 or MEK inhibitor U0219 which inhibits downstream JAK2 induced pathways [13] known to phosphorylate unliganded ER $\alpha$ at S118 and S167 had no effect (Figure 4A and 4B). THZ1 effectively abolished $\mathrm{E}_{2}$ induced $\mathrm{ER} \alpha$ recruitment to the PRLR hPIII promoter (Figure 4D) and consequently caused a marked reduction of $\mathrm{E}_{2}$-induced PRLR transcription to control levels (Figure 4C). This clearly indicated the role of $\mathrm{pER} \alpha$ (S118) and the essential requirement of CDK7 in the transcriptional upregulation of the PRLR receptor induced by $\mathrm{E}_{2}$ (Figure 4C).

Endogenous prolactin is essential for activation of pSTAT5a which its presence at the DNA site is required for the recruitment and stability of the complex. This has been established in ChIP studies where PRL was knock-down by siRNA and recruitment of STAT5a was effectively reduced at its site in the promoter. In this instance a major reduction was observed on ER $\alpha$ and $\mathrm{C} / \mathrm{EBP} \beta$ induced by $\mathrm{E}_{2}$. In the absence of $\mathrm{E}_{2}$ significant reductions on ER $\alpha$ recruitment to hPIII (basal) (Figure $3 \mathrm{~A})$ was also observed in this study as in our previous studies on the unliganded ER $\alpha$ [13] with PRL knockdown, which are comparable to the basal values in this study (Figure 3A). This led us to propose a role for endogenous PRL/PRLR/STAT5 and of STAT5a interaction in the stability of the complex. This proposal has been demonstrated in this study where $\mathrm{E}_{2}$ recruitment of $E R \alpha$ to the complex was significantly reduced with PRL knock-down. In addition, basal and $\mathrm{E}_{2}$ stimulated $\mathrm{C} / \mathrm{EBP} \beta$ were similarly reduced (Figure $3 \mathrm{~A}-3 \mathrm{C}$ ). The efficiency of C/EBP $\beta$ recruitment to its DNA site was greatly enhanced when $\mathrm{ER} \alpha / \mathrm{Sp} 1$ complexes were preformed and DNA-bound Sp1 was the preferred interacting partner of ER $\alpha$ [18]. However, the reduction of Sp1 recruitment was not expected since it appeared to be associated to the complex constitutively and not 
A.

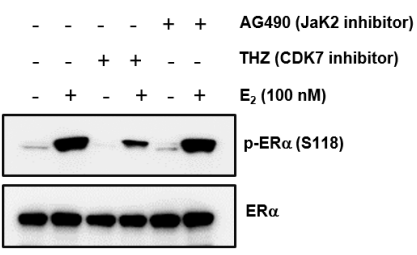

C.

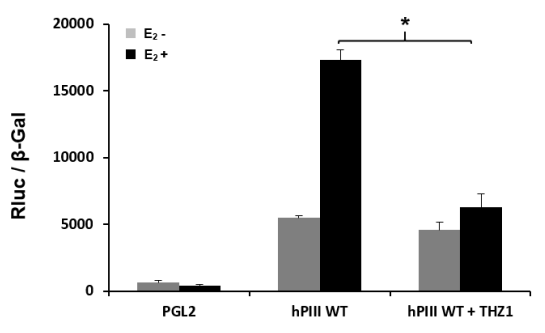

B.

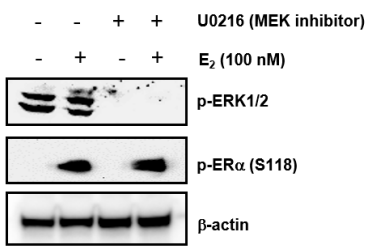

D.

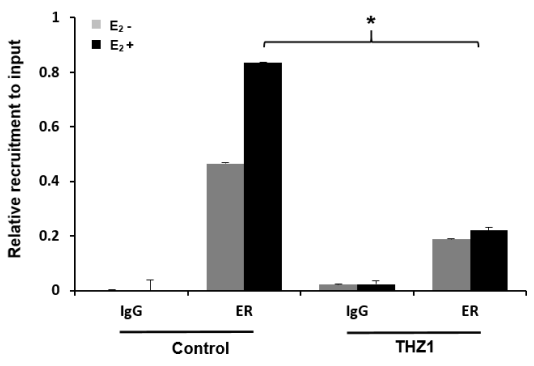

Figure 4: Role of CDK-7 in E2 induced promoter activity. (A) Representative Western blot showing the phosphorylation status of ER $\alpha$ at serine 118 (S118) in MCF-7 cells in controls and after treatment with the CDK7 inhibitor, THZ1 (100 nM), or AG-490 (100 $\mu \mathrm{M}$ ) for $3 \mathrm{~h}$ prior to $\mathrm{E}_{2}$ treatment for $30 \mathrm{~min}$. Endogenous $\mathrm{ER} \alpha$ and $\beta$-actin are used as loading controls. (B) Western blot showing effect of $\mathrm{U} 0126(10 \mu \mathrm{M})$ on phosphorylation status of ER $\alpha$ at S118 and ERK1/2 in cells cultured in presence or absence of $\mathrm{E}_{2}$ for 30 min following pre-incubation with or without inhibitor. $\beta$-actin is used as loading control. (C) Effect of CDK-7 inhibitor on $\mathrm{E}_{2}$ induced upregulation of hPIII transcriptional activity. MCF-7 cells transfected with PGL2 vector (control) or with hPIII promoter construct were pre-incubated with or without THZ1 $(100 \mathrm{nM})$ inhibitor for $3 \mathrm{~h}$ prior to addition of $\mathrm{E}_{2}$ and further incubated for $18 \mathrm{~h}$. Results presented are relative luciferase activities (RLuc) normalized to the activities of co-transfected $\beta$-galactosidase. Asterisks $(*)$ indicate statistically significant changes between $\mathrm{E}_{2}$ untreated and treated groups (Student $t$-test; $\left.P<0.001\right)$. (D) Effect of THZ1 (100 nM) treatment of cells as in $($ C) on $\mathrm{E}_{2}$-induced recruitment of $\mathrm{ER} \alpha$ to the complex at the promoter assessed by ChIP assay.

A.
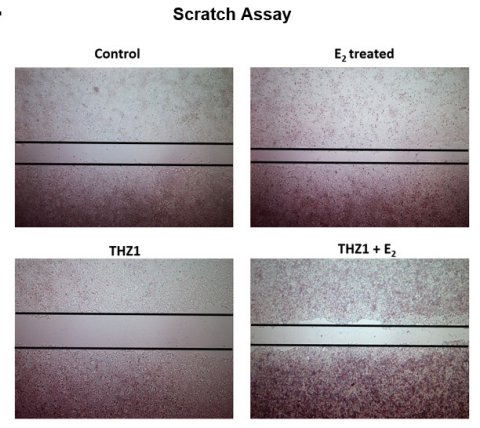

$\mathrm{THZ1}+\mathrm{E}_{2}$
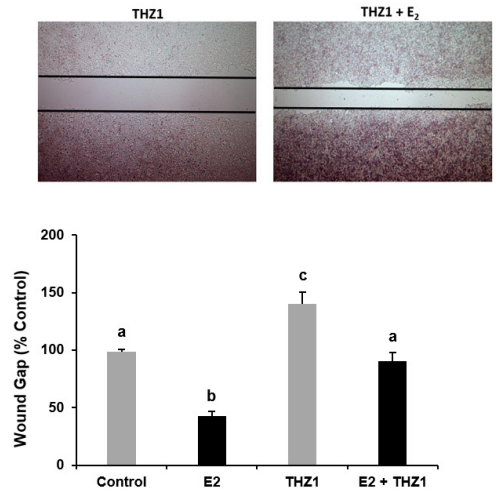

B.

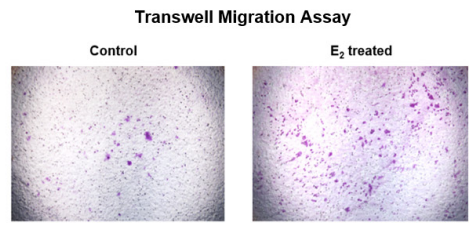

THZ
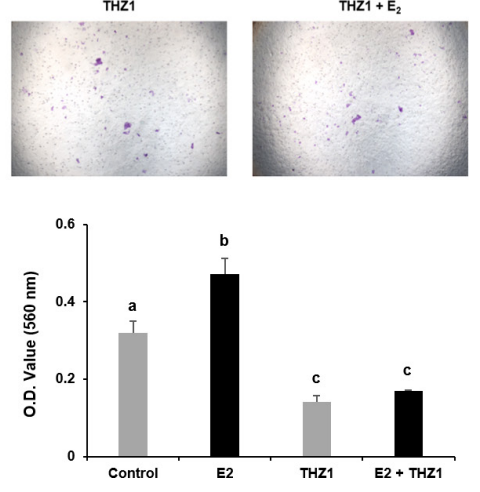

Figure 5: Effect of CDK-7 treatment on E2 induced MCF-7 cell migration by Scratch (A) and Trans-well (B) assays. (A) MCF-7 cells pre-incubated with THZ1 $(100 \mathrm{nM})$ for $3 \mathrm{~h}$ were subjected to scratch/wound healing assay to assess the $\mathrm{E}_{2}$ induced cell migration. After $48 \mathrm{~h}$ photographs were taken and wound width was calculated using ImageJ software. Representative images showing the wound width in control and treated groups. Graph showing the wound gap (percentage of control) in different groups. Different superscript letters indicate statistical significance between experimental groups (Tukey's multiple comparison test, $P<0.05$ ). (B) Effect of THZ1 (100 nM) on migration induced by $\mathrm{E}_{2}$ assessed by Transwell assay following pre-treatment of MCF7 cells with THZ1 for three hours (see methods). Below Relative absorbance of lyzed cells detected on migrated membranes. Different superscript letters indicate statistical significance between experimental groups (Tukey's multiple comparison test, $P<0.05$ ). Data represents the Mean $\pm \mathrm{SE}$ from three independent experiments. 

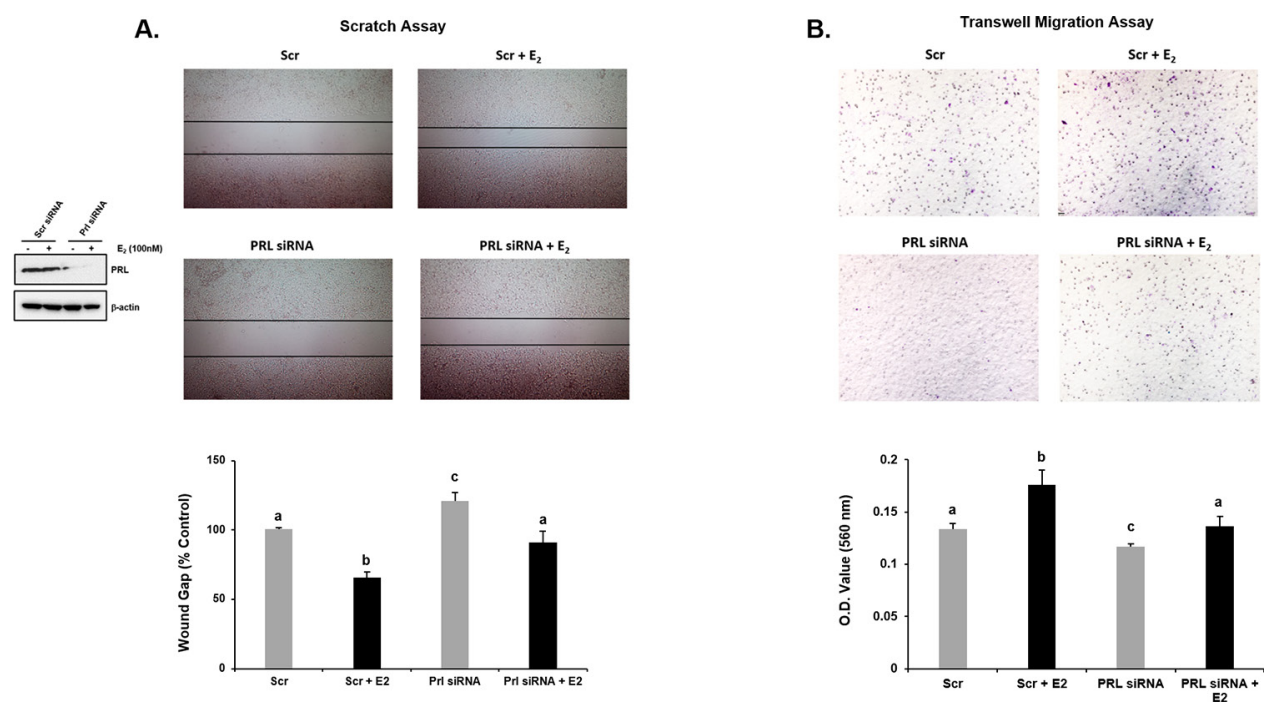

Figure 6: Effect of PRL knockdown on E2 induced MCF-7 cell migration by Scratch (A) and Trans-well (B) assays. (A) Left siRNA and control treated with Scr siRNA were assessed for $\mathrm{E}_{2}$ - induced cell migration. MCF-7 cells transfected with Scr or PRL siRNA were subjected to scratch/wound healing assay to assess the $\mathrm{E}_{2}$ induced cell migration. After $48 \mathrm{~h}$ photographs were taken and wound width was calculated using ImageJ software. Representative images showing the wound width in control and treated groups. Graph showing the wound gap (percentage of control). Different superscript letters indicate statistical significance between experimental groups (Tukey's multiple comparison test, $P<0.05$ ). (B) Effect of PRL siRNA knock-down on migration induced by $\mathrm{E}_{2}$ assessed by Transwell assay. Below Relative absorbance of corresponding to lyzed cells present on migrate membranes. Different superscript letters indicate statistical significance between experimental groups (Tukey's multiple comparison test, $P<0.05$ ).

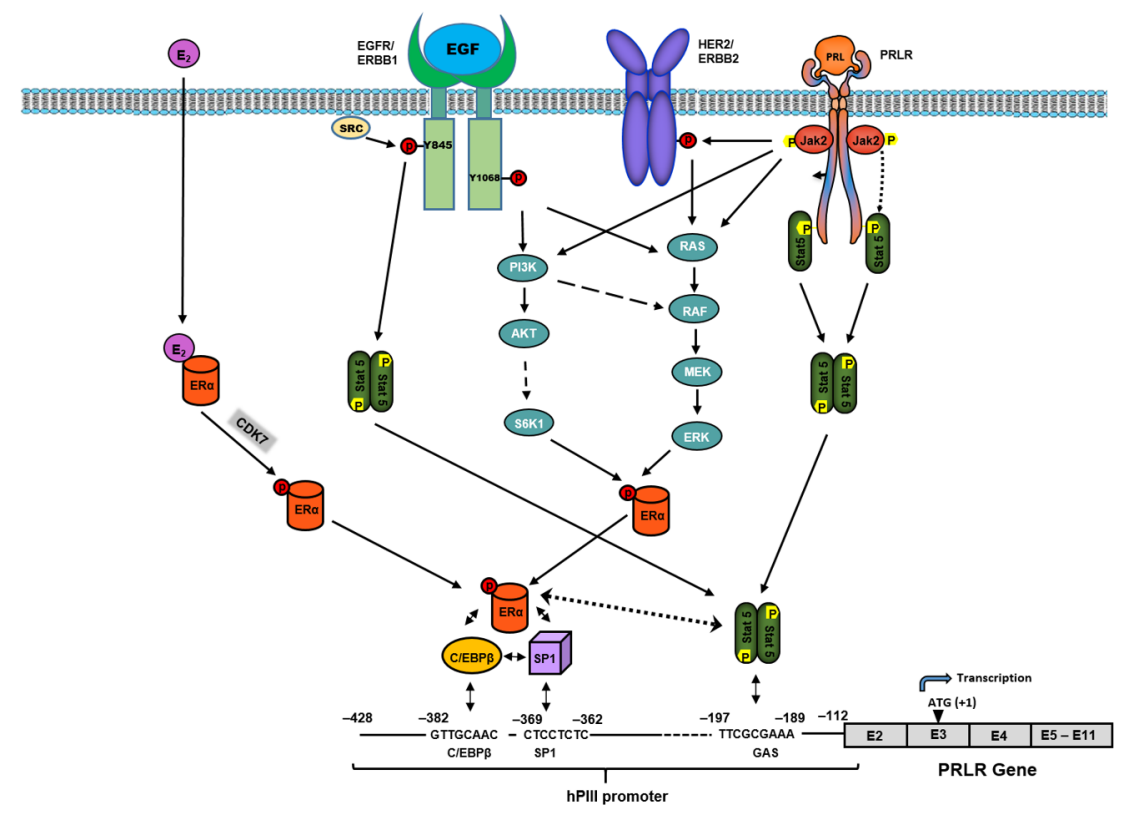

Figure 7: Mechanisms of the upregulation of hPRLR induced by E2/ER $\alpha$ revealed in this study and others defined in our previous studies [13, 19] Requirement of association of $\mathrm{pER} \alpha(\mathrm{S} 118)$ induced by E2 via phosphorylation by CDK7 (non-DNA bound) and complex formation with C/EBP/Sp1 bound to their respective DNA elements at the hPIII promoter. PRL/PRLR is essential for transcriptional activation of PRLR through activation of STAT5 which associates its site at the hPIII promoter and stabilizes the complex by association with ER $\alpha$, a requirement for recruitment of coactivators, TFIIB and Pol II [12]. Inhibition of $\mathrm{pER} \alpha(\mathrm{S} 118)$ by the $\mathrm{CDK} 7$ inhibitor causes abolition complex formation and of transcription/expression. The use of this inhibitor could provide an alternative efficacious adjuvant therapy to prevent inductive and progression effects of $\mathrm{E}_{2} / \mathrm{ER}_{\alpha}$ in breast cancer. Also, presented schematically are other previously described modalities on the up-regulation of PRLR via PRL/PRLR/JAK2/STAT5 per se, or through HER2 [13] transactivation by JAK2. In addition, are shown EGF functional effects via its cognate receptor ERBB1, independent of PRL/PRLR and E2 [19], on the activation of intrinsic receptor tyrosine kinase and signal transduction pathways participating in STAT5 and ER $\alpha$ phosphorylation/activation, respectively, -essential for PRLR gene transcription through hPIII promoter. 
Table 1: Comparative summary of mechanisms of upregulation of PRLR induced by $E_{2}$, PRL and EGF through liganded and un-liganded pER $\alpha$ and STAT5

\begin{tabular}{|c|c|c|c|}
\hline Phosphorylation & $\mathbf{E}_{2}$ & PRL* & EGF** \\
\hline $\mathbf{E R} \alpha$ & Cdk 7 (S118) & $\begin{array}{l}\text { 1) PRLR/JAK2/PI3K/MEK/ERK } \\
\text { (S118; S167) } \\
\text { 2) PRLR/JAK2/HER2-HER3/ } \\
\text { RAS/RAF/MEK1/2/ERK (S118; } \\
\text { S167) } \\
\text { 3) JAK2/HER2-HER3/ PI3K/ } \\
\text { AKT/S6K1 (S118; S167) }\end{array}$ & $\begin{array}{l}\text { 1) ERBB1 1068,1086 RAS/ } \\
\text { RAF/MEK/ERK (S118) } \\
\text { 2) ERBB1 1068, } 1086 \\
\text { PI3K/AKT/mTOR/ S6K1 } \\
\text { (S167) }\end{array}$ \\
\hline STAT5 & $\begin{array}{l}\text { PRL/PRLR/JAK2 } \\
\text { pSTAT5a }\end{array}$ & $\begin{array}{l}\text { PRL/PRLR/JAK2 } \\
\text { pSTAT5a \& pSTAT5b }\end{array}$ & $\begin{array}{l}\text { EGF/ERBB1Y845 c-SRC } \\
\text { pSTAT5b }\end{array}$ \\
\hline
\end{tabular}

*independent of $\mathrm{E}_{2} ; * *$ independent of $\mathrm{E}_{2}$ and PRL

$\mathrm{ER} \alpha$ Serine (S) (phospho-position)

Table 2: List of validated siRNAs used for gene knockdown and their sequence information

\begin{tabular}{ll}
\hline Gene & Sequence (Sense) \\
\hline PRL & GCGAAUUCGAUAAACGGUATT \\
STAT5a & AUGGAUAUGUGAAACCACATT \\
STAT5b & CACCCGCAAUGAUUACAGUTT \\
Scrambled siRNA & AATTCTCCGAACGTGTCACGT \\
\hline
\end{tabular}

shown to be induced by $\mathrm{E}_{2}$ in previous $[12,18]$ and this study Figure $3 \mathrm{C}$. The absence of stabilization of the complex by reduction of STAT $5 \mathrm{a} / \mathrm{ER} \alpha$ interaction could reduce the recruitment $\mathrm{C} / \mathrm{EBP} \beta$ and $\mathrm{Sp} 1$. In this regard studies where $\mathrm{C} / \mathrm{EBP} \beta$ was depleted with siRNA in cells treated in presence or absence of $\mathrm{E}_{2}$ a marked reduction of Sp1 association to its DNA site was observed when compared to control. Thus, the association of ER $\alpha$ to $\mathrm{Sp} 1$ seems to be important for recruitment of $\mathrm{C} / \mathrm{EBP} \beta$ to its site and in turn $\mathrm{C} / \mathrm{EBP} \beta$ and $-\mathrm{Sp} 1$ associations secure the stable recruitment of $\mathrm{Sp} 1$ and the overall complex formation (Figure 7).

The mechanism of upregulation of PRLR by $\mathrm{E}_{2} / \mathrm{ER} \alpha$ defined in this study displays commonalties and specific differences with those described for unliganded ER $\alpha$ and EGF/EGFR [13, 19]. Although mechanistically all require STAT5 association with hPIII the specific STAT5 class participation which associates to hPIII reveal differences, STAT5a and b or specifically STAT5a, in both cases where involvement of prolactin was required and STAT5b in the case of EGF/EGFR participation. This may be related in part to specific requirements for their phosphorylation which is a requisite for their recruitment to its site at hPIII and/or presumably for their interaction with ER $\alpha$. Also, differences in modality of phosphorylation of ER $\alpha$ have been indicated above and summarized in Table 1 .
Recent studies using kinase inhibitors and gene editing demonstrated that triple-negative breast cancer cells are transcriptional dependent on CDK7. A cluster of genes in these cells were found to be exquisitely sensitive to the CDK7 inhibitor THZ1 [22]. In this regard, it is of interest that the inhibition of $\mathrm{CDK} 7$ which participates in the phosphorylation of $\mathrm{ER} \alpha$ at $\mathrm{S} 118$ require for $\mathrm{E}_{2}$ induced upregulation of PRLR, also effectively inhibited the wellknown induction of cell migration induced by $\mathrm{E}_{2}$ (Figures 5 and 6). Prolactin as $\mathrm{E}_{2}$ through similar mechanism has been reported to promote cell migration [23-25]. This was further established in this study by knock-down of endogenous PRL which resulted in inhibition of $\mathrm{E}_{2}$-induced cell migration. This indicated a dependence on PRL/PRLR on $\mathrm{E}_{2}$-induced cell migration and their mutual link to $\mathrm{CDK} 7$ participation (Figure 6). Targeting CDK7 kinase, which is known to regulate both transcription and the cell cycle and ER $\alpha$ phosphorylation with the THZ1 inhibitor was found to effectively inhibit the transcription of the PRLR and its contribution to cell migration induced $\mathrm{E}_{2} / \mathrm{ER} \alpha$ in breast cancer cells. THZ1 treatment could provide an additional avenue singly or in combination with other inhibitory approaches targeting receptor function (PRLR [26], ER $\alpha$ [13]), HER2 [27], ERBB1 [19]) and/or signaling pathways (MAPK, PI3K, c-SRC [13, 19], ERBB1Tyrosine kinase, [19]) to effectively ablate transcription of PRLR and its contribution to breast cancer. 


\section{MATERIALS AND METHODS}

\section{Reagents and antibodies}

Phenol-red free RPMI 1640 media and RPMI 1640-GlutaMAX were purchased from ThermoFisher Scientific. Charcoal/Dextran treated Fetal Bovine Serum (FBS) was obtained from Atlanta Biologicals. STAT5a, STAT5b, STAT5, ER $\alpha, \beta$-actin antibodies and AG-490 (JAK2 inhibitor) were obtained from Santa Cruz Biotechnology. Phospho (p)-ERK1/2, and U1026 (MEK1/2 inhibitor) were from Cell Signaling and the CDK7 inhibitor, THZ1 hydrochloride from Med Chem Express. pER $\alpha$ (Ser118) antibody was obtained from EMD Millipore. PRLR antibody were obtained from Sigma-Aldrich. Human PRL antibody were obtained from National Hormone and Peptide Program, Harbor-UCLA Med. Ctr., Torrance, CA 90502.

\section{Cell culture and reporter gene assay}

The MCF-7A2 (MCF-7) ER positive breast cancer cells (gift from E. Berleth, C. Roswell Park Cancer Institute, New York, NY) were maintained in RPMI 1640-GlutaMAX supplemented with $10 \%$ charcoal stripped $\mathrm{FBS}$ at $37^{\circ} \mathrm{C}$ in $\mathrm{CO}_{2}$ incubator. Cells were cultured in 24 well plates using phenol red-free RPMI media with $5 \%$ and $1 \%$ charcoal-treated FBS for 2 days at each serum concentration. The PRLR generic promoter (hPIII promoter/non-coding exon $1\left[\mathrm{hE} 1_{3}\right]$ ) with reporter pGL2 gene construct (bp -480/-112) containing C/EBP $\beta$, $\mathrm{Sp} 1$ sites in $\mathrm{hPIII}$ and putative STAT5 binding site in $\mathrm{hE} 1_{3}$, and construct with the STAT5 site mutated, and pGL2 empty vector were used for transient transfection in MCF7 cells using Lipofectamine 3000 reagent (ThermoFisher Scientific) as described previously [18]. Cells were treated with $\mathrm{E}_{2}(100 \mathrm{nM})$ in RPMI phenol red-free media for 18 h. To study the effect of CDK-7 inhibitor (THZ1) on the PRLR generic promoter activity, cells pre-incubated with THZ1 for $3 \mathrm{~h}$ prior treatment with $100 \mathrm{nM} \mathrm{E}_{2}$ and incubation for $24 \mathrm{~h}$. Cells were harvested to the determine PRLR promoter activity using Brigh-Glo luciferase assay system (Promega). The $\mathrm{E}_{2} 100 \mathrm{nM}$ dose used in the present studies was derived from our previous work demonstrating that addition of $\mathrm{E}_{2}(1-100 \mathrm{nM})$ to the cultures caused dose dependent increases in PRLR promoter activity, mRNA and protein [12].

\section{Cell-migration assays}

\section{Wound healing/scratch assay}

MCF-7 cells $\left(5 \times 10^{4}\right.$ cells/well) were cultured in 6 well plates with phenol red free RPMI media containing $5 \%$ charcoal stripped $\mathrm{FBS}$ at $37^{\circ} \mathrm{C}$ in $\mathrm{CO}_{2}$ incubator. Then next day cells were transfected with $20 \mathrm{nM}$ scrambled and PRL silencer select siRNAs using siPORTNeoFX reagent (Life Technologies) and grown in 1\% charcoal stripped FBS till cells reach $90 \%$ confluent. Then cell monolayers were wounded by scratching with sterile $100 \mu \mathrm{L}$ micropipette tips. Fresh medium containing $100 \mathrm{nM} \mathrm{E}_{2}$ was added every $12 \mathrm{~h}$. After $48 \mathrm{~h}$ cells were photographed under phase contrast inverted microscope and cell migration was assessed by measuring migration distance (wound gap) using ImageJ Software from National Institutes of Health. To study the effect of THZ1 inhibitor on cell migration, cells were pre-incubated with the inhibitor for $3 \mathrm{~h}$ prior treatment with $\mathrm{E}_{2}$.

\section{Transwell assay}

MCF-7 cells were cultured and transfected as indicated above and incubated in presence or absence of THZ1 inhibitor for $3 \mathrm{~h}$. Transwell assay was performed using $6.5 \mathrm{~mm}$ inserts with $8 \mu \mathrm{m}$ pore size polycarbonate membrane inserts (Cell Biolabs, Inc). Subsequently, 0.5 X $10^{6}$ cells in $300 \mu$ of RPMI phenol red free were seeded on the top chamber and $500 \mu \mathrm{R}$ RMI containing 10\% charcoal-treated FBS with or without $\mathrm{E}_{2}(100 \mathrm{nM})$ was applied to the lower chamber. Migration was assessed after incubation of culture plates at $37^{\circ} \mathrm{C}$ in a $5 \% \mathrm{CO} 2$ incubator for 24-48 h. After removal of non-migrated cells from the upper chamber, membranes were fixed in methanol for $5 \mathrm{~min}$. The cells that are migrated to the lower side of the membrane were stained with cell stain solution (crystal violet) provided in the kit for $5 \mathrm{~min}$. The migrated cells were by visualized under a light microscopy and photograph at $5 \mathrm{X}$ magnification. Also, migrated cells were lyzed using $200 \mu \mathrm{l}$ of extraction solution and the absorbance at $560 \mathrm{~nm}$ was recorded for indirect estimation of the number of migrated cells [28].

\section{Western blot analysis}

Whole cell lysates from MCF-7 cells cultured in serum starved conditions in presence and absence of $\mathrm{E}_{2}(100$ $\mathrm{nM})$ or treated with U0126 $(10 \mu \mathrm{M})$ or THZ1 $(100 \mathrm{nM})$ inhibitors were extracted using RIPA lysis buffer (Thermo Scientific, Rockford, IL) in presence of $1 \mathrm{x}$ protease and Phosphatase inhibitor cocktail (Thermo Scientific). The protein samples were run on NuPAGE $4-12 \%$ Bis-Tris gradient gels and transferred to nitrocellulose membranes using iBlot 2 (ThermoFisher Scientific). Membranes were blocked with 5\% skimmed milk powder in phosphate buffer saline and incubated with different primary antibodies or $\beta$-actin (loading control) and washed and incubated with secondary antibody conjugated with HRP (Pierce). Immunodetection was performed using super-signal chemiluminescence system (Pierce).

\section{siRNA analysis}

Silencer Select pre-designed validated siRNAs from Ambion (ThermoFisher Scientific) were used to knock- 
down the endogenous expression of PRL, STAT5a, STAT5b in MCF-7 cells. Scrambled siRNA was used as negative control. The MCF-7 cells were transfected with $20 \mathrm{nM}$ siRNA using siPORTNeoFX or Lipofectamine RNAiMAX reagent (ThermoFisher Scientific) as described previously [18]. After $48 \mathrm{~h}$ of siRNA transfection cells were grown in $5 \%$ charcoal treated FBS for 1 day and $1 \%$ for additional 2 days. The cells were harvested for Chip assays and Western blots after treatment with $\mathrm{E}_{2}(100 \mathrm{nM})$ in serum free medium for $18 \mathrm{~h}$. All the Silencer Select siRNA sequences used for RNAi interference are shown in Table 2.

\section{Chromatin immunoprecipitation (ChIP) assay}

MAGnify $^{\mathrm{TM}}$ Chromatin Immunoprecipitation system from Invitrogen was used to perform ChIP assays according to the manufacturer's protocol as described previously [18]. The relative binding of $\mathrm{Sp} 1, \mathrm{C} / \mathrm{EBP} \beta$ and STAT5 proteins to their respective putative DNA binding sites on PRLR promoter was quantitatively evaluated by qRT-PCR of the precipitated DNA and input DNA using SYBER Green FAST Master Mix in an ABI 7500 Fast Real-Time PCR system. The primers used for amplification of the PRLR promoter sequence that spans the STAT5 site and Sp1 and C/EBP $\beta$ sites are 5'GCATG CTGAAGAAAATCACTGTTTTGCC3' (forward) and 5' TGCACGAGGACATGAAGCTCCA 3' (reverse).

\section{Statistical analysis}

The significance of the differences among groups were determined by multiple Tukey's multiple-comparison test (one-way ANOVA) and significance of the differences between $\mathrm{E}_{2}$ treated versus control were determined by Student's $t$-test using the Prism software program (GraphPad Software, Inc, San Diego, California)

\section{ACKNOWLEDGMENTS}

This work was supported by the NIH Intramural Research Program through the Eunice Kennedy Shriver National Institute for Child Health and Human Development.

\section{CONFLICTS OF INTEREST}

The authors declare no conflicts of interest.

\section{REFERENCES}

1. Finidori J, Kelly PA. Cytokine receptor signaling through two novel families of transducer molecules: Janus kinases, and signal transducers and activators of transcription. J Endocrinol. 1995; 147:11-23.

2. Qazi AM, Tsai-Morris CH, Dufau ML. Ligand-independent homo- and heterodimerization of human prolactin receptor variants: inhibitory action of the short forms by heterodimerization. Mol Endocrinol. 2006; 20:1912-1923.

3. Aksamitiene E, Achanta S, Kolch W, Kholodenko BN, Hoek JB, Kiyatkin A. Prolactin-stimulated activation of ERK1/2 mitogen-activated protein kinases is controlled by PI3-kinase/Rac/PAK signaling pathway in breast cancer cells. Cell Signal. 2011; 23:1794-1805.

4. Touraine P, Martini JF, Zafrani B, Durand JC, Labaille F, Malet C, Nicolas A, Trivin C, Postel-Vinay MC, Kuttenn F. Increased expression of prolactin receptor gene assessed by quantitative polymerase chain reaction in human breast tumors versus normal breast tissues. J Clin Endocrinol Metab. 1998; 83:667-674.

5. Meng J, Tsai-Morris CH, Dufau ML. Human prolactin receptor variants in breast cancer: low ratio of short forms to the long-form human prolactin receptor associated with mammary carcinoma. Cancer Res. 2004; 64:5677-5682.

6. Wennbo H, Tornell J. The role of prolactin and growth hormone in breast cancer. Oncogene. 2000; 19:1072-1076.

7. Howell A. Clinical evidence for the involvement of oestrogen in the development and progression of breast cancer. Proceedings of the Royal Society of Edinburgh. Section B. Biological Sciences. 1989; 95:49-57.

8. Spink BC, Bennett JA, Pentecost BT, Lostritto N, Englert NA, Benn GK, Goodenough AK, Turesky RJ, Spink DC. Long-term estrogen exposure promotes carcinogen bioactivation, induces persistent changes in gene expression, and enhances the tumorigenicity of MCF-7 human breast cancer cells. Toxicol Appl Pharmacol. 2009; 240:355-366.

9. Saha Roy S, Vadlamudi RK. Role of estrogen receptor signaling in breast cancer metastasis. Int J Breast Cancer. 2012:654698.

10. Giretti MS, Fu XD, De Rosa G, Sarotto I, Baldacci C, Garibaldi S, Mannella P, Biglia N, Sismondi P, Genazzani AR, Simoncini T. Extra-nuclear signalling of estrogen receptor to breast cancer cytoskeletal remodelling, migration and invasion. PLoS One. 2008; 21;3:e2238.

11. Yue W, Yager JD, Wang JP, Jupe ER, Santen RJ. Estrogen receptor-dependent and independent mechanisms of breast cancer carcinogenesis. Steroids. 2013; 78:161-70.

12. Dong J, Tsai-Morris CH, Dufau ML. A novel estradiol/ estrogen receptor alpha-dependent transcriptional mechanism controls expression of the human prolactin receptor. J Biol Chem. 2006; 281:18825-18836.

13. Kavarthapu R, Tsai Morris CH, Dufau ML. Prolactin induces upregulation of its cognate receptor in breast cancer cells via transcriptional activation of its generic promoter by cross-talk between ER $\alpha$ and STAT5. Oncotarget. 2014; 5:9079-9091. doi: 10.18632/oncotarget.2376.

14. Hu ZZ, Zhuang L, Meng J, Dufau ML. Transcriptional regulation of the generic promoter III of the rat prolactin receptor gene by C/EBPbeta and Sp1. J Biol Chem. 1998; 273:26225-35. 
15. Hu ZZ, Zhuang L, Meng J, Leondires M, Dufau ML. The human prolactin receptor gene structure and alternative promoter utilization: the generic promoter hPIII and a novel human promoter hP(N). J Clin Endocrinol Metab. 1999; 84:1153-6.

16. Hu ZZ, Zhuang L, Meng J, Tsai-Morris CH, Dufau ML. Complex 5' genomic structure of the human prolactin receptor: multiple alternative exons 1 and promoter utilization. Endocrinology. 2002; 143:2139-42.

17. Leondires MP, Hu ZZ, Dong J, Tsai-Morris CH, Dufau ML. Estradiol stimulates expression of two human prolactin receptor isoforms with alternative exons-1 in T47D breast cancer cells. J Steroid Biochem Mol Biol. 2002; 82:263-8.

18. Kang JH, Tsai-Morris CH, Dufau ML. Complex formation and interactions between transcription factors essential for human prolactin receptor gene transcription. Mol Cell Biol. 2011; 31:3208-3222.

19. Kavarthapu R, Dufau ML. Role of EGF/ERBB1 in the transcriptional regulation of the prolactin receptor independent of estrogen and prolactin in breast cancer cells. Oncotarget. 2016; 7:65602-65613. doi: 10.18632/ oncotarget.11579.

20. Chen D, Washbrook E, Sarwar N, Bates GJ, Pace PE, Thirunuvakkarasu V, Taylor J, Epstein RJ, Fuller-Pace FV, Egly JM, Coombes RC, Ali S. Phosphorylation of human estrogen receptor alpha at serine 118 by two distinct signal transduction pathways revealed by phosphorylation-specific antisera. Oncogene. 2002; 21:4921-4931.

21. Kwiatkowski N, Zhang T, Rahl PB, Abraham BJ, Reddy J, Ficarro SB, Dastur A, Amzallag A, Ramaswamy S, Tesar B, Jenkins CE, Hannett NM, McMillin D, et al. Targeting transcription regulation in cancer with a covalent CDK7 inhibitor. Nature. 2014; 511:616-620.

22. Wang Y, Zhang T, Kwiatkowski N, Abraham BJ, Lee TI, Xie S, Yuzugullu H, Von T, Li H, Lin Z, Stover DG, Lim E, Wang ZC, et al. CDK7-dependent transcriptional addiction in triple-negative breast cancer. Cell. 2015; 163:174-186.

23. Ho JY, Chang FW, Huang FS, Liu JM, Liu YP, Chen SP, Liu YL, Cheng KC, Yu CP, Hsu RJ. Estrogen Enhances the Cell Viability and Motility of Breast Cancer Cells through the ER $\alpha-\Delta$ Np63-Integrin $\beta 4$ Signaling Pathway. PLoS One. 2016;11:e0148301.

24. Sun Y, Wang Y, Fan C, Gao P, Wang X, Wei G, Wei J. Estrogen promotes stemness and invasiveness of ER-positive breast cancer cells through Gli1 activation. Mol Cancer. 2014; 13:137. doi: 10.1186/1476-4598-13-137.

25. da Silva PL, do Amaral VC, Gabrielli V, Montt Guevara MM, Mannella P, Baracat EC, Soares-Jr JM, Simoncini T. Prolactin Promotes Breast Cancer Cell Migration through Actin Cytoskeleton Remodelling. Front Endocrinol (Lausanne). 2015; 6:186. doi: 10.3389/fendo.2015.00186.

26. Damiano JS, Wasserman E. Molecular pathways: blockade of the PRLR signaling pathway as a novel antihormonal approach for the treatment of breast and prostate cancer. Clin Cancer Res. 2013; 19:1644-50.

27. Arteaga CL, Sliwkowski MX, Osborne CK, Perez EA, Puglisi F, Gianni L. Treatment of HER2-positive breast cancer: current status and future perspectives. Nat Rev Clin Oncol. 2011; 9:16-32.

28. Kramer N, Walzl A, Unger C, Rosner M, Krupitza G, Hengstschläger M, Dolznig H. In vitro cell migration and invasion assays. Mutat Res. 2013; 752:10-24. 